\title{
Adrenergic fibres in the human intestine
}

\author{
L. CAPURSO, ${ }^{1}$ C. A. FRIEDMANN, AND A. G. PARKS \\ From the Research Department, St Mark's Hospital, London, and the London Hospital, \\ Whitechapel, London
}

The application of histochemical methods specific for acetylcholinesterase (Koelle, 1955) and for catecholamines (Falck, 1962; Falck and Owman, $1965)$ to the study of intestinal innervation has provided a clearer understanding of cholinergic and adrenergic function in this tissue. Thus, it was shown (Donhoffer, 1959) that the ganglion cells of the intestinal plexuses which give rise to postganglionic fibres innervating the smooth muscle usually contain acetylcholine as transmitter substance. When fluorescent histochemical techniques were used for identifying catecholamines, it was shown, in the cat and the rat, that the major part of the adrenergic fibres at the level of the enteric plexuses is disposed around these ganglia. The muscular coats appear to receive only a small number of adrenergic fibres, mainly distributed in the walls of the blood vessels (Norberg, 1964; Norberg and Sjöqvist, 1966; Hamberger and Norberg, 1956). In the mucosa only occasional adrenergic fibres were observed, whereas around the mucosal glands numerous cells were seen containing 5-hydroxytryptamine. Similar observations have been made in the gastric mucosa of the rat (Håkanson, Lilja, and Owman, 1967).

A large number of cholinergic fibres and a comparative scarcity of adrenergic fibres have been reported in the intestine of the cat and the monkey (Jacobowitz, 1965), but a rich adrenergic innervation has been found in the duodenum of the rat, the distal colon and ileo-caecal sphincter of the rabbit, and the taenia coli of the guinea pig (Hollands and Vanov, 1965).

We have applied similar histofluorescent methods to a study of the sympathetic innervation of the human intestine.

\section{MATERIALS AND METHODS}

Twenty-two pieces of intestinal muscle were examined (one jejunum, two ileum, one ascending colon, three transverse colon, 12 sigmoid, and three rectal), also seven pieces of mucosa (six sigmoid, one rectal) obtained

'Present address: Institute of Medical Pathology, Gastroenterology Group, University of Rome. at operation from patients suffering from rectal carcinoma. All specimens were taken from areas which appeared normal macroscopically.

\section{METHOD}

The tissue was frozen in a propane-propylene mixture cooled to $-150^{\circ} \mathrm{C}$ in liquid nitrogen. It was stored at $-35^{\circ} \mathrm{C} / 0 \cdot 1-0.001 \mathrm{~mm}$ of mercury pressure in the presence of phosphorus pentoxide. By this technique of preliminary rapid cooling, tissue damage by formation of ice crystals was minimized. After five to six days the temperature was raised to 50 to $60^{\circ} \mathrm{C}$, the vacuum broken, and the specimens were removed. They were immediately embedded in paraffin under reduced pressure at $56^{\circ} \mathrm{C}$ for 10 to 15 minutes. Sections, 7 to $10 \mu$ thick, were cut in the usual way, either parallel to the mucosal surface or transverse to it. They were then exposed to formaldehyde vapour generated from paraformaldehyde previously equilibrated over $60 \%$ sulphuric acid in order to provide an atmosphere containing a minimal amount of water vapour. They were mounted on thin glass slides and the paraffin wax was removed by the application of liquid paraffin at $60^{\circ} \mathrm{C}$ on a hot plate.

Formation of fluorescence from the different catecholamines depends upon both time of reaction and temperature. Generally, primary catecholamines, eg, noradrenaline, fluoresce well after exposure to formaldehyde vapour for one hour at $80^{\circ} \mathrm{C}$, whereas exposure for at least three hours was necessary in the case of secondary catecholamines. Catecholamine fluorescence is rapidly quenched with sodium borohydride thus differentiating it from other forms of tissue fluorescence.

\section{RESULTS}

The structural elements of the myenteric plexus appear to be surrounded by intensely fluorescent fibres. In the plexus itself there are cellular elements (Fig. 1) which bear a striking resemblance to the ganglion cells in the superior ganglion of the rabbit (Fig. 2) in that the central zone is non-fluorescent but the perikaryon contains rich deposits of noradrenaline.

Some fluorescent fibres appear to originate in the myenteric plexus and to terminate in the longitudinal and circular muscles (Figs. 3 and 4), but the 


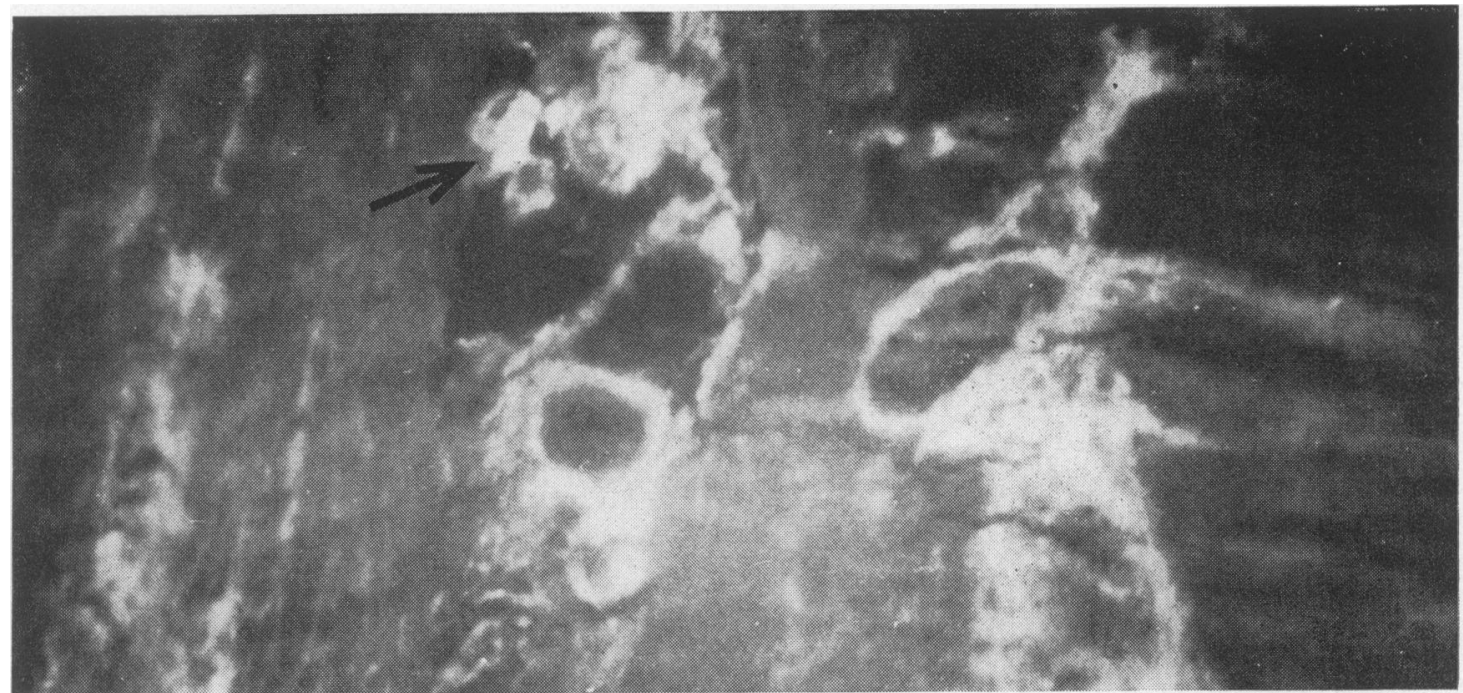

FIG. 1.

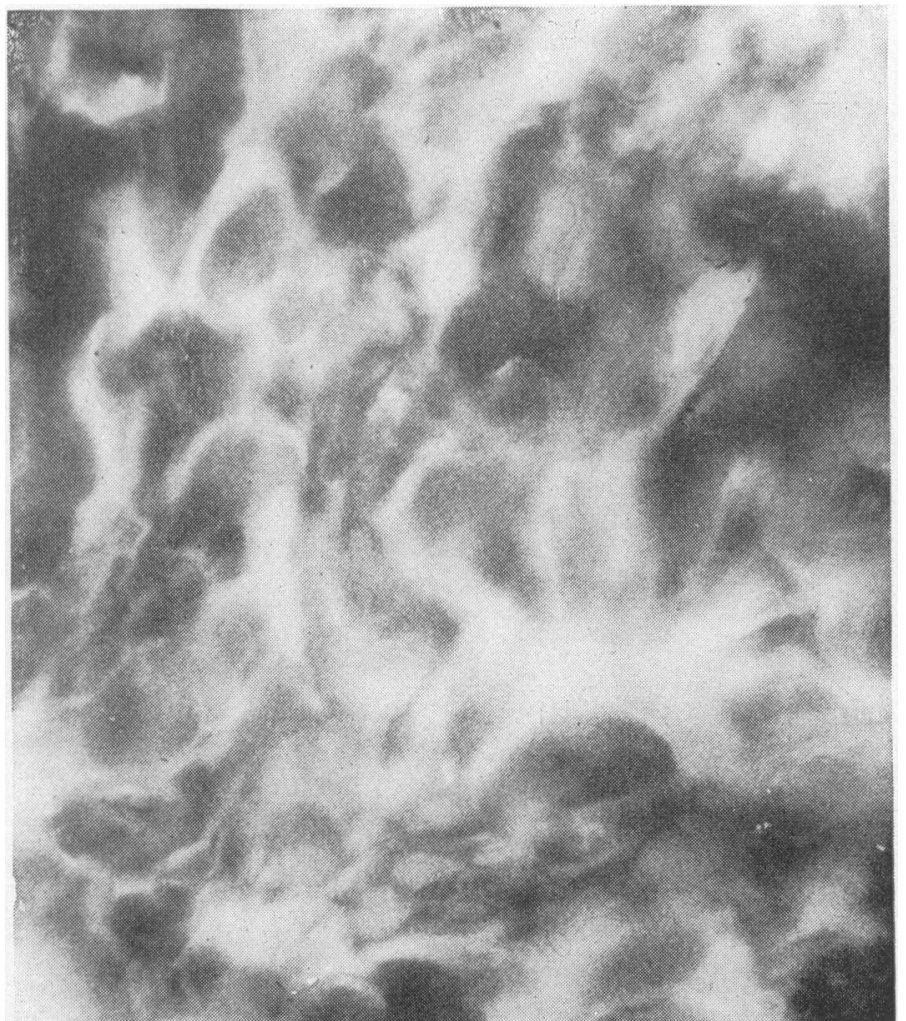

FIG. 1. Section through the region of the myenteric plexus of the human sigmoid colon. Clear spaces surrounded by fluorescence suggest ganglion cells.

FIG. 2. Section of superior cervical ganglion of the rabbit shows ganglion cells surrounded by fluorescent fibres.

FIG. 2. 


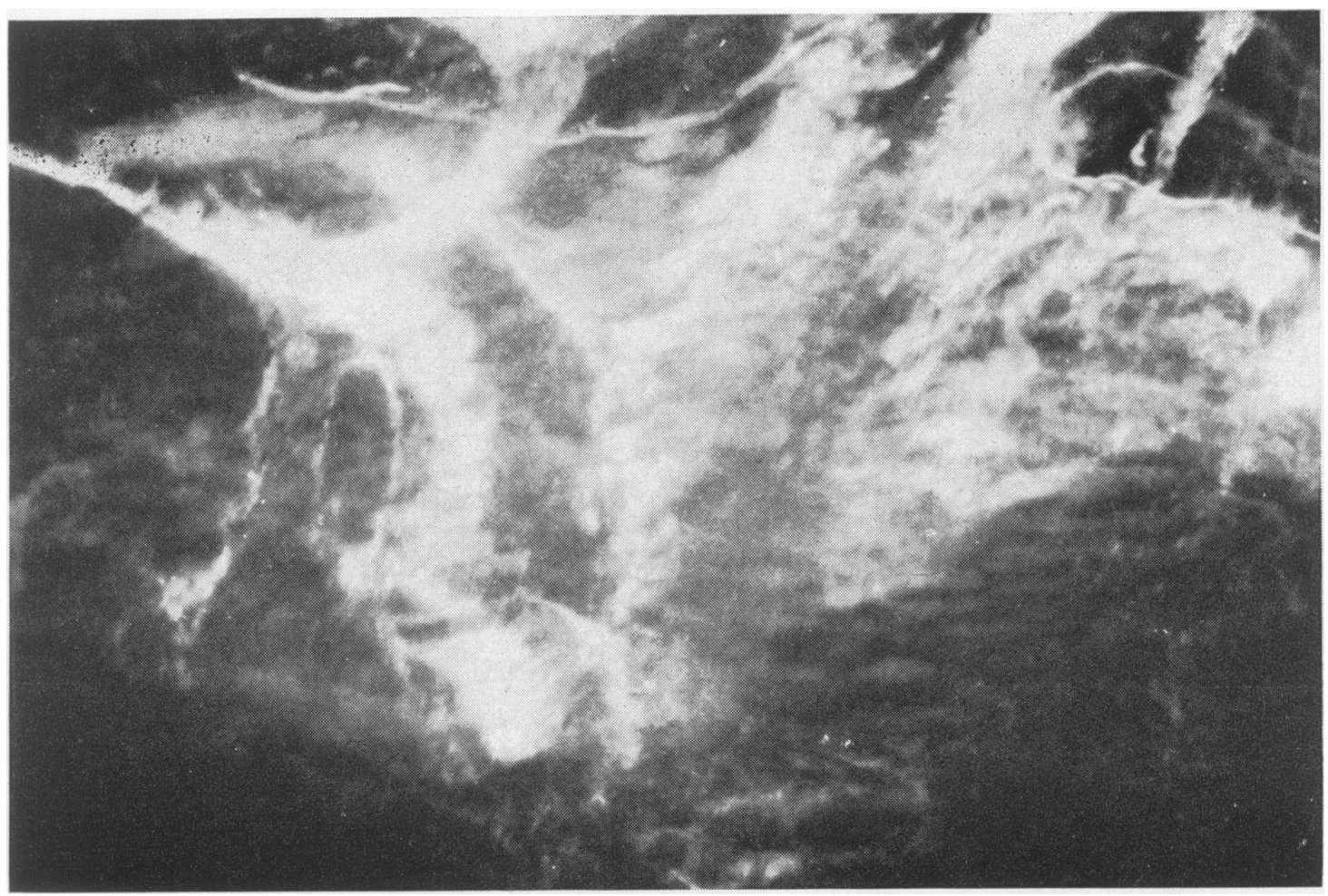

FIG. 3. Adrenergic fibres are passing from the myenteric plexus to the circular muscle of the intestine.

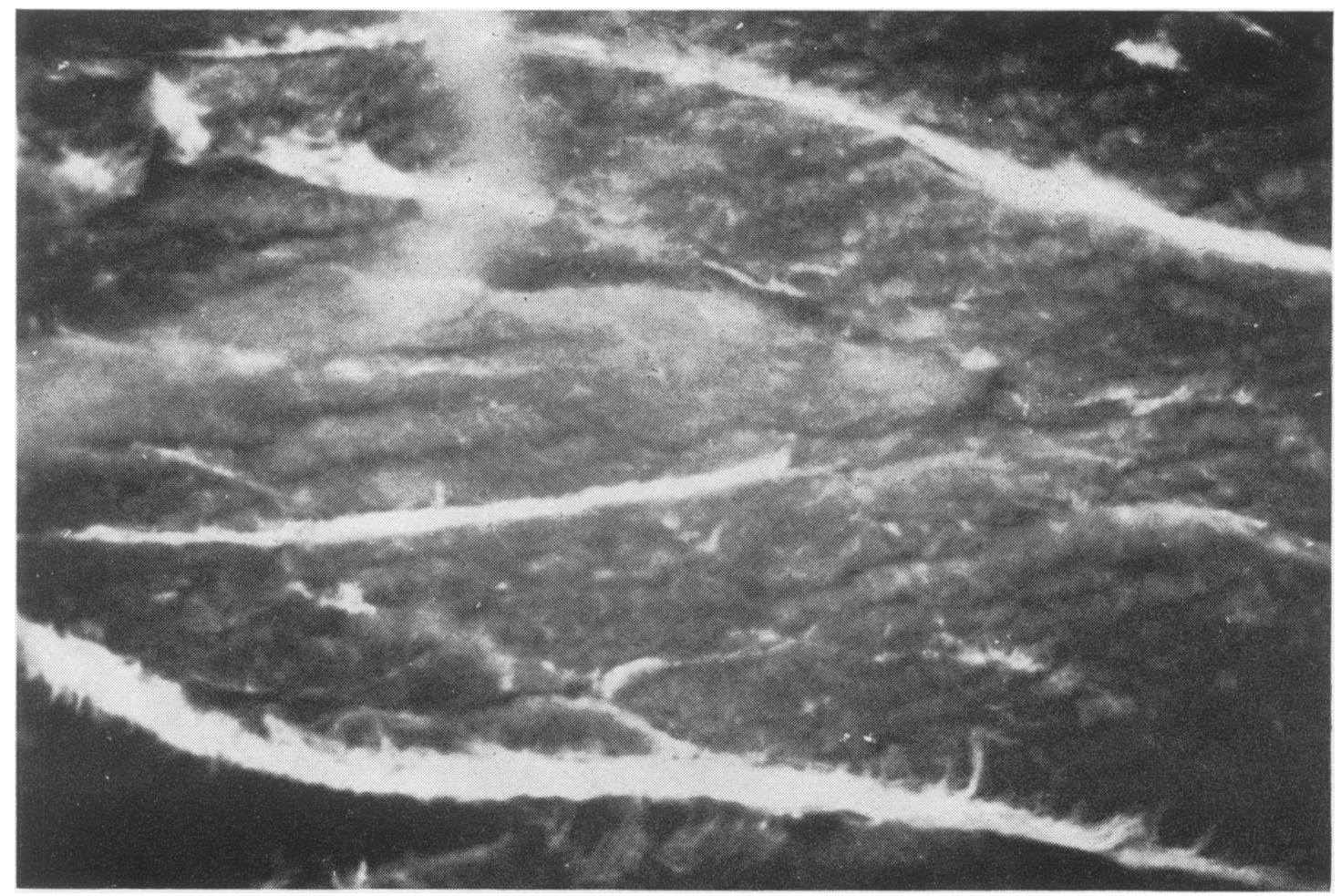

FIG. 4. Strands of adrenergic fibres are seen passing through circular muscle. 


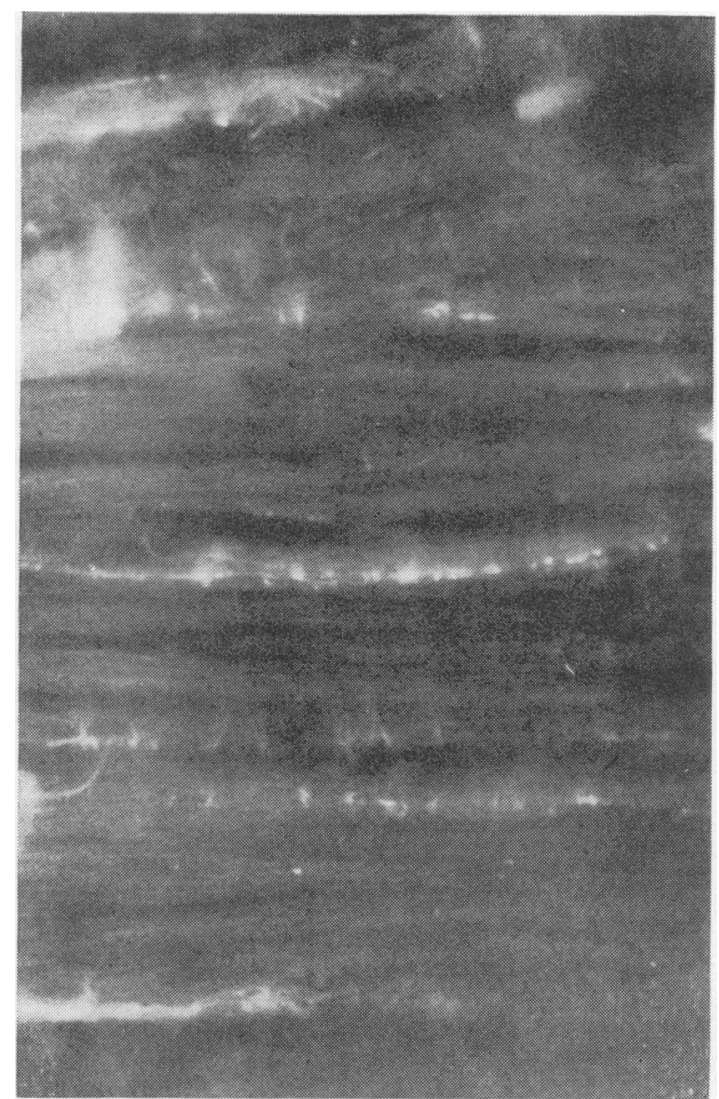

FIG. 5. Slender nerve fibres are running longitudinally between muscle fibres. Noradrenaline-containing granules can be seen.

adrenergic innervation of the muscle coats does not appear to be very rich. The fibres are slender and straight and run parallel to the muscle fibres without collateral branches. In some cases it was possible to distinguish the noradrenaline-containing granules distributed along the nerve fibres (Fig. 5). The mucosa also occasionally contains adrenergic structures.

\section{DISCUSSION}

Our results appear to indicate that the cellular elements in the myenteric plexus are not uniquely cholinergic in man but are frequently enveloped by a rich store of catecholamines. The sympathetic innervation of the intestinal musculature is sparsely distributed and we see these fibres rarely. In some cases it has been possible to see these adrenergic fibres originating in the zone of the myenteric plexus and continuing towards the muscle. The whole course has not so far been followed.
It has been suggested (Norberg, 1964; Norberg and Sjöqvist, 1966) that the sympathetic inhibition of the intestine involves a chain of three neurones: the first is preganglionic and cholinergic with its cellular body in the spinal cord. The second is postganglionic and adrenergic, with its cellular body in the prevertebral ganglion and with its termination in the intramural intestinal ganglion. The third is a parasympathetic, postganglionic neurone in the intestinal wall. These views are supported by the observations (Jacobowitz, 1965) that there are more cholinergic than adrenergic fibres in the intestine of the cat and the monkey.

The application of two staining techniques to the same section, one for catecholamines and one for acetylcholinesterase, should help to clarify this interrelationship. This technique has already been applied to sympathetic ganglia in the cat where it has been observed that a certain number of ganglion cells show both an intense fluorescence for catecholamines as well as a tenuous reaction for acetylcholinesterases (Hamberger, Norberg, and Sjöqvist, 1965). The nature of the actions mediated by these cells remains to be shown. Similar observations have been made in the sympathetic ganglia of the rat (Eränkö and Härkönen, 1964) and in the rat iris (Eränkö and Räisänen, 1965; Ehinger and Falck, 1965).

Some authors have examined the possibility of a peripheral interaction between adrenergic and cholinergic neurones (Leaders, 1963, Leaders and Dayrit, 1965). Such combined staining and fluorescent techniques may help in showing whether there are fibres which subserve both cholinergic and adrenergic function simultaneously.

\section{SUMMARY}

The use of histofluorescent techniques specific for catecholamines and for 5-hydroxytryptamine has shown that in the human gut the myenteric plexus contains cellular elements which are enveloped by structures rich in catecholamines. Adrenergic fibres are also present in the mucosa.

This work has been supported by the Medical Research Council of Great Britain.

\section{REFERENCES}

Donhoffer, A. (1959). Feinere lokalisation verschiedener cholinesterasen der nervösen darmgeflechte. Acta morph. Acad. Sci., 8, 375-379.

Ehinger, B., and Falck, B. (1965). Noradrenaline and cholinesterases in concomitant nerve fibres in the rat iris. Life Sci., 4, 20972100.

Eränkö, O., and Härkönen, M. (1964). Noradrenaline and acetylcholinesterase in sympathetic ganglion cells of the rat. Acta physiol. scand., 61, 299-300. 
Eränko, O., and Räisänen, L. (1965). Fibres containing both noradrenaline and acetylcholinesterase in the nerve net of the rat iris. Ibid., 63, 505-506.

Falck, B. (1962). Observations on the possibilities of the cellular localization of monoamines by a fluorescence method. Ibid., 56, suppl. 197.

- , and Owman, C. (1965). A detailed methodological description of the fluorescence method for the cellular demonstration of biogenic monoamines. Acta Univ. Lund., sect. II, no. 7.

Håkanson, R., Lilja, B., and Owman, C. (1967). Properties of a new system of amine-storing cells in the gastric mucosa of the rat. Europ. J. Pharmacol., 1, 188-199.

Hamberger, B., and Norberg, K. A. (1965). Studies on some systems of adrenergic synaptic terminals in the abdominal ganglia of the cat. Acta physiol. scand., 65, 235-242.

- - — , and Sjöqvist, F. (1965). Correlated studies of monoamines and acetylcholinesterase in sympathetic ganglia, illustrating the distribution of adrenergic and cholinergic neurons. Proceedings of the IInd international Pharmacological Meeting, Prague, 1963. Edited by H. Raskova. Pergamon Press, Oxford.
Hollands, B. C. S., and Yanov, S. (1965). Localization of catecholamines in visceral organs and ganglia of the rat, guinea-pig and rabbit. Brit. J. Pharmacol., 25, 307-316.

Jacobwitz, D. (1965). Histochemical studies of the autonomic innervation of the gut. J. Pharmacol.exp. Ther., 149, 358-364.

Koelle, G. B. (1955). The histochemical identification of acetylcholinesterase in cholinergic, adrenergic and sensory neurons. Ibid., 114, 167-184.

Leaders, F. E. (1963). Local cholinergic-adrenergic interaction: mechanism for the biphasic chronotropic response to nerve stimulation. Ibid., 142, 31-38.

- and Dayrit, C. (1965). The cholinergic component in the sympathetic innervation to the spleen. Ibid., 147, 145-152.

Norberg, K. A. (1964). Adrenergic innervation of the intestinal wall studied by fluorescence microscopy. Int. J. Neuropharmacol., 3, 379-382.

_ ation of ganglionic transmission. Pharm. Rev., 18, 743-751. 